\title{
"Puede más un cacique que çien frailes juntos". Representaciones de los señores étnicos en los escritos toledanos
}

\footnotetext{
"An ethnic lord can do more than a hundred friars together". Representations of the ethnic lords in Toledan writings
}

\author{
Natividad Ferri Carreres \\ Équipe de recherche sur les Littératures, les Imaginaires et les Sociétés (ERLIS) \\ Université de Caen, Normandie-FRANCIA \\ nati.ferri@hotmail.fr
}

\section{Resumen:}

En este trabajo examinamos el rol atribuido a los "señores" étnicos en la obra literaria y jurídica escrita y promovida por Francisco de Toledo. Para ello, en primer lugar, presentamos el marco teórico en el que se inscribe el pensamiento toledano. Posteriormente, manejamos tres fuentes: dos de tipo literario que se cotejan entre sí, el Parecer anónimo de Yucay y la Relación sumaria de lo que se contiene en la información de la tiranía de los yngas; y una de carácter jurídico, las Ordenanzas. La confrontación de los tres documentos nos permite enfatizar una imagen de los "señores" étnicos cargada de ambivalencias y contradicciones. Llegamos a la conclusión de que la imagen vehiculada en estos documentos y el rol asignado a los señores étnicos, además de enmarcarse dentro de una estrategia legitimadora de la soberanía de la Corona, forman parte de una maniobra personal en la que Toledo pretendía justificar su misión reformadora ante las voces críticas que se elevaban contra él.

Palabras clave: Francisco de Toledo, literatura y derecho, "señores étnicos", estrategias, ambivalencias.

\begin{abstract}
In this paper we examine the role attributed to the ethnic lords in the literary and legal works written and promoted by Francisco de Toledo. To this end, we first present the theoretical framework in which Toledo's thought is inscribed. Then, we analyze three sources: two of literary type that are compared among themselves, the Parecer anónimo de Yucay and the Relación sumaria de lo que se contiene en la información de la tiranía de los yngas; and one of juridical character, the Ordenanzas. The confrontation of these three documents lets us emphasize an image of the ethnic lords loaded with ambivalences and contradictions. We reach the conclusion that the image conveyed by these documents and the role assigned to the ethnic lords, besides being framed within a strategy that legitimizes the sovereignty of the Crown, are part of a personal maneuver in which Toledo tried to justify his reforming mission before the critical voices that
\end{abstract}


were raised against him.

Keywords: Francisco de Toledo, literature and law, "ethnic lords", strategies, ambivalences.

Recibido: 17 de noviembre de 2020 - Aceptado: 25 de enero de 2021

\section{Introducción}

Treinta años después de la conquista, nada funcionaba en el Perú: los encomenderos, enzarzados en interminables conflictos y a menudo ausentes de sus encomiendas, no lograban garantizar la explotación económica; los señores étnicos (también llamados caciques o curacas), aprovechando este desorden, ejercían a menudo un poder abusivo sobre los indios; la resistencia indígena no cedía, y la práctica de la idolatría parecía más viva que nunca. La población indígena había disminuido debido a las epidemias y los trabajos forzados, y además, durante estos años la Corona tuvo que afrontar la cuestión espinosa de los justos títulos, muy disputada desde la corriente lascasiana. Era vital, pues, recuperar el control de los intereses coloniales, sofocar las rebeliones, y establecer un buen método de evangelización para poner fin a la idolatría y a la mala gestión de la Iglesia en materia de evangelización.

Por lo demás, para garantizar el éxito del mundo colonial, se tuvo que recurrir a un sistema de gobierno indirecto, apoyado en gran medida en las élites indígenas o señores étnicos. La Corona tuvo la necesidad de mantener el estatus quo de estos "señores" para administrar las colonias, lo que dio lugar a que ciertos autores hablaran de "pacto de reciprocidad” (Tandeter, 1992: 42; Platt, 1982:
23-35). Mediante este "pacto" implícito, la Corona otorgaba cierto margen de libertad política a los señores y, en contrapartida, éstos trabajaban para que el Rey les permitiera adaptar ciertas estructuras prehispánicas dentro del orden colonial. Como sugiere Marina Zuloaga (2012:105-109), durante la dominación española los caciques se mantuvieron por tres razones. Primero, por el respeto al pacto político establecido, que implicaba la aceptación de la autoridad del encomendero. Segundo, por la cristianización, que fue bastante rápida gracias a ellos, y que los introdujo en el círculo del poder al adquirir derechos políticos e igualdad jurídica; $y$ por último, por la legitimidad que los indios reconocieron en sus antiguos curacas, lo que facilitó la imposición de las nuevas leyes.

Existen numerosas pruebas testimoniales del amplio poder que lograron alcanzar ciertos caciques, sobre todo aquellos que habían tenido a su cargo cacicazgos prehispánicos o que se habían aliado con los conquistadores en el momento de su llegada, y que asumieron protagonismo en los primeros repartos de encomiendas. Por ejemplo, el cacique Astochava, de la región de Jauja, "estuvo muchos años en posesión del dicho cacicazgo [de la guaranga de Ichochonta] hasta que por su muerte lo heredó D. Lorenzo Malqui Yanan hijo del dicho Astochava" (Zuloaga, 2012: 100). Con los años, muchos caciques aprovecharon su poder 
para reivindicar antiguos derechos mediante probanzas e incluso algunos escribieron memoriales al rey (Espinosa, 1984: 183). Otros, como Felipe Guacrapáucar, cacique del valle de Jauja, decidieron ir en persona a la Corte. Guacrapáucar, navegó a España en 1563 para entrevistarse con Felipe II y reivindicar varios derechos, entre los cuales estaba ser nombrado alcalde mayor del valle de Jauja, ser encomendero del repartimiento de Lurinhuanca, tener facultad para nombrar a nualmente alcaldes ordinarios, regidores y alguaciles, y poseer título de propiedad de todas las tierras baldías. Felipe II le acordó varias cédulas reales para su beneficio y el de sus administrados (Espinosa, 1984: 183-184).

Lo cierto es que hacia finales de 1560, los señores étnicos habían alcanzado cotas elevadas de podery algunos atizaban incluso asaltos y levantamientos. En 1564, las autoridades eran advertidas de una posible conspiración patrocinada desde Vilcabamba por Titu Cusi, el Inca rebelde ${ }^{1}$, y organizada en la región de Jauja, con ramificaciones en Cuzco, Chucuito y Potosí (Lohmann Villena, 1957: 41). Un año después, el gobernador del Perú, Lope García de Castro, enviaba un memorial a Felipe II en el que informaba que los indios estaban haciendo preparativos sospechosos a menudo orquestados por señores étnicos (Levillier, 1921b, III: 54-69). García de Castro insistía en que estos "preparativos" estaban además apoyados en levantamientos que habían estallado en Chile y Tucumán, protagonizados por Diaguitas, Juríes y Chiriguanos con la ayuda del Inca rebelde. Todo parecía apuntar a un complot general. La amenaza había alcanzado Tarija, a sólo 15 leguas de Potosí donde García de Castro temía que "si estos se desasosiegan no paran en las minas de Potosí los yndios que en ellas andan y perdería Vuestra magestad trescientos mil pesos cada año y se perderían todos los de este Reyno" (Levillier, 1921b, III: 56).

No cabe duda de que los caciques estaban asumiendo un rol demasiado preponderante que podía poner en peligro la estabilidad colonial. En este contexto de desorden, el 27 de julio de 1568 tuvo lugar en Madrid la celebración de la Junta Magna ${ }^{2}$, compuesta por teólogos y juristas de todos los Consejos, de la que emanaron una serie de requerimientos que buscaban reorganizar el Perú en lo tocante, principalmente, a la evangelización y las encomiendas. De hecho, el propio Bartolomé de las Casas (1565: 537) en un Memorial dirigido al Consejo de Indias poco antes de morir, ya había anticipado la necesidad de que se convocase una congregación de letrados teólogos y juristas para poner remedio al mal estado de las Indias.

La Junta Magna estuvo impulsada por el entonces presidente del Consejo de Castilla e Inquisidor General, el cardenal de Sigüenza, Diego de Espinosa, muy próximo al rey Felipe II. La responsabilidad de llevar a cabo la ardua misión de reorganizar el virreinato fue asignada al recién nombrado virrey del Perú, Francisco de Toledo, quien se congratuló de las resoluciones tomadas en la Junta señalando que su Majestad cumpliría así "con las obligaciones que debe y tiene en aquellas provincias" (Levillier, 1935b, III: 32). Toledo contaba así con el apoyo de la máxima autoridad política y religiosa de la Corona: el monarca y el Inquisidor General. En un momento histórico que simbolizaba el sometimiento definitivo del 
virreinato del Perú, Francisco de Toledo emprendió una labor encaminada a minar la legitimidad de los señores étnicos durante el periodo incaico, a quienes consideraba los principales adalides de la tiranía de los Incas. Pero, lejos de eliminar su poder, redefinió su autoridad dentro del orden colonial, acotándola jurídicamente.

Este trabajo analiza las razones que llevaron al virrey Francisco de Toledo a construir diversas representaciones de los señores étnicos en las obras literarias y de orden jurídico, auspiciadas o escritas por él. Nos apoyamos para nuestro estudio en tres fuentes. Las dos primeras son el Parecer Anónimo de Yucay [1571] y y la Relación sumaria sobre la tiranía de los Ingas [1572] ${ }^{4}$, contenida en las Informaciones que Toledo mandó hacer durante su visita; el tercer documento corresponde a sus Ordenanzas. Sobre la base de los primeros documentos pretendemos presentar la imagen que estos escritos elaboraron de los señores étnicos que gobernaban bajo el dominio de los incas y los motivos que hicieron que Toledo construyera tal imagen. Apoyándonos en las Ordenanzas, subrayaremos el giro de política que el virrey experimentó en la valoración del rol de los señores étnicos, a quienes, dentro del orden colonial, atribuyó legitimidad a su autoridad. Nuestra intención, pues, es demostrar que estos escritos y leyes proyectaron dos imágenes contradictorias de los señores étnicos acorde a los intereses políticos y personales del virrey.

Descartamos conscientemente de nuestro estudio dos obras que de alguna manera también contribuyeron a difundir una imagen tiránica de los señores étnicos: Gobierno del Perú (1567) de Juan de Matienzo e Historia Indica (1572) de Pedro Sarmiento de Gamboa. Tanto Matienzo como Sarmiento de Gamboa formaron parte del equipo de consejeros de Toledo. Sabido es que las Instrucciones y Ordenanzas del virrey estuvieron influenciadas por el Gobierno del Perú, tratado jurídico que planteó, más de una década antes de la llegada de Toledo, la condición de los Indios y la reestructuración colonial, constituyendo un precedente a las políticas del virrey. Esta obra ha sido ampliamente estudiada por Germán Morong (2013; 2016; 2019). Por su parte, la Historia Índica ${ }^{5}$ de Pedro Sarmiento fue enviada a la corte de Felipe II en 1572 junto con los Paños sobre la genealogía de los incas que Toledo encargó pintar. Sin embargo, pese a formar parte del proyecto político del virrey junto con el Parecer y las Informaciones, la Historia Índica se sitúa dentro de la corriente etno-historiográfica de las crónicas y queda, por lo tanto, fuera de la bibliografía que hemos decidido emplear para nuestro trabajo, centrado en memorias, leyes y pareceres personales.

\section{La literatura toledana al servicio de la Corona}

Toledo llega al Perú como alter ego del monarca dispuesto a hacer valer la soberanía de la Corona, muy discutida por algunos sectores de la Iglesia. Gracias a los poderes que le había conferido la Junta Magna, el virrey ideó un plan de choque para acabar con los males que azotaban el territorio, a saber: los enemigos internos de la Corona, representados por la corriente lascasiana y los encomenderos; los señores étnicos que habían alcanzado elevadas cotas de poder; el bastión de resistencia de Vilcabamba; y las guerras con 
los indios de la frontera oriental de los Andes (Merluzzi, 2014:180).

El 19 de marzo de 1569, Toledo partió desde Sanlúcar de Barrameda hacia Lima, donde llegó un 30 de octubre, después de haber permanecido varios meses en la región de Panamá. Iba acompañado de clérigos, del tribunal de la Inquisición, y de varios frailes de órdenes religiosas, ente ellos fray García de Toledo, primo hermano del virrey (Levillier, 1935b, III: 21).

Llegó el virrey a Lima convencido de la labor que le esperaba, sentimiento que expresaba en estas líneas: "hasta que no se consuma y acabe el govierno con que se a proçedido en esta tierra [...] y se plante y saque otro de nuevo nunca se podrá asentar estas provinçias" (Levillier, 1921b, III: 304). Consciente de la inmensidad del territorio, decidió emprender personalmente la tarea de visitarlo manifestando un empeño insólito por conocer los pueblos y las costumbres indígenas, lo que consideraba indispensable antes de ejecutar cualquier ordenanza. Así lo manifestaba en el memorial de Gobierno escrito al final de su mandato:

Cuando Su Magestad me mandó que fuese al gobierno de aquella tierra [...] para poderlo ejecutar tuve necesidad de entender su modo de vivir y gobierno y sus costumbres, tratos y comercios, y conocer sus inclinaciones y naturaleza [...] y hasta haber visto y entendido lo que en ella había proveí muy poco (Beltrán y Rózpide, 1921: 82).
Toledo había llegado para poner fin al desorden que reinaba y legitimar la presencia de la Corona, y lo hizo señalando en primer lugar a Bartolomé de las Casas como responsable de los daños producidos en aquellos reinos. En una carta al Cardenal Espinosa del 25 de marzo de 1571 afirmaba que "la primera raíz del fundamento de todo el daño del gobierno desta tierra, [...] fue [...] la indiscreta inexperiencia que el obispo de Chiapas avía hecho con su persuasión en esos rreynos" (Mustapha, 1977: 226). Esta misma idea aparece también en el Parecer de Yucay, donde la acusación contra Las Casas es más directa:

Con este favor que tuvo y autoridad [Las Casas] persuadió a toda España [...] del dominio y señorío destos Ingas [...] y dioles título de legítimos reyes desta tierra [...]. Que persuadió y escribió con tan grandes inconvenientes como han sucedido [...] si su Magestad no fuera alumbrado de la verdad, que es haber sido el Inga uno de los mayores tiranos del mundo y más fresco (Pérez Fernández, 1995: 117).

El 23 de octubre de 1570, Toledo emprende su visita al territorio, la cual se extendió durante 5 años. En 1572, año bisagra marcado por el fin del bastión rebelde de Vilcabamba y la ejecución de Tupac Amaru, Toledo hizo llegar al "rey prudente" cuatro documentos: sus Informaciones; la Historia General llamada Índica, escrita de mano de su cosmógrafo Pedro Sarmiento de Gamboa; unos lienzos (los famosos Paños) que ilustraban la genealogía de los gobernantes; y el Parecer Anónimo de Yucay. Los cuatro documentos forman parte de lo que podríamos llamar la historiografía Toledana anti 
inca, y aunque no todos los textos fueron escritos por el virrey, sí fueron fuertemente incitados por él. Estos trabajos estaban destinados a demostrar la tiranía con que los incas habían gobernado y corroborar la soberanía de la Corona. Toledo así lo dejaba patente en su Relación sumaria6: “[...] que vuestra Magestad es legitimo Señor destos reynos y los yngas y curacas tiranos como tales intrusos en el gobierno dello" (Giménez de la Espada, 1882: 201).

La visita constituye un estudio etnológico del mundo indígena plasmado en un cuestionario que sus oficiales realizaban a la población, y que ha llegado a nuestros días como las Informaciones en averiguación del origen y gobierno de los incas. Estas podrían ser consideradas una fuente indígena, aunque, huelga decirlo, con un importante sesgo colonial. Por lo tanto, debemos examinarlas con precaución ya que, como sugiere Merluzzi (2008a: 10) "se trata [...] de testimonios que los indígenas prestaban frente a funcionarios de la Monarquía, es decir, sus nuevos dominadores", quienes previamente habían redactado los cuestionarios. Estas Informaciones servirán de base a las postreras ordenanzas y leyes dictadas por los virreyes.

Se trata de un conjunto de once Informaciones, con interrogatorios a un público escogido, $\mathrm{y}$ utilizando preguntas bien predefinidas que inducían a respuestas inequívocas cuyo objetivo primordial era demostrar los títulos ilegítimos que ostentaban los incas en el Perú. Por falta de espacio, no detallaremos aquí estos cuestionarios, que requerirían consagrarles un artículo completo. Nos limitaremos a utilizar la Relación sumaria con la que Toledo acompañó el envío de sus Informaciones a Felipe II y que constituye una síntesis de las mismas.

Pese a que Toledo pone el foco en desprestigiar a los señores étnicos, cabe notar que para dar credibilidad a sus interrogatorios, les concede un alto protagonismo a dichos señores en sus escritos. Sirva de ejemplo la carta del 25 de marzo de 1571 al Consejo de Indias, en la que Toledo anuncia el envío de una Información de sesenta testigos, "los de mayor edad y más principales de autoridad y crédito que yo he hallado en este reyno [...] para que vuestra alteza entienda una verdad que desde allí entendí ser muy necesaria [...] para el gobierno destos reynos" (Levillier, 1921b, III: 443). En su Relación sumaria finalizada el 1 de marzo de 1572, el virrey repite que había realizado sus Informaciones "con [...] testigos destos naturales, de los más viejos y ancianos y de mejor entendimiento que se han podido hallar, de los cuales muchos son caciques y principales, y otros de la descendencia de los Ingas que hubo en esta tierra" (Giménez de la Espada, 1882: 186). Nótese la insistencia por probar que sus Informaciones se habían extraído a partir de interrogatorios realizados a "caciques y principales", en un afán por aportar peso y veracidad a sus testimonios. Pero sorprende cómo esos mismos señores a quienes confiere autoridad son tachados también de tiranos, como veremos más adelante.

El Parecer Anónimo de Yucay, datado en el Valle de Yucay a 16 de marzo de 1571 se inserta también dentro de la historiografía toledana anti inca. Según Pérez Fernández (1995:78)7 , el autor probable fue fray García de Toledo, primo del virrey, que 
le acompañó al Perú como secretario y le asistió durante toda la visita. Según Monique Mustapha, el propio virrey parece confirmar la autoría del Parecer en una carta escrita el 25 de marzo de 1571 , en la que afirmaba que adjunta a las dos Informaciones realizadas hasta el momento "un cuadernillo que a fray García de Toledo mandé hacer sobre esta materia, en que, con cuidado e inquisición, se ha ocupado" (Mustapha, 1977: 226).

\section{Los gobernantes incas en el pensamiento de Toledo: ¿tiranos o civilizadores?}

El pensamiento de Toledo se nutre de una corriente literaria influida por las ideas de Aristóteles y basada en el modelo del Espejo de Príncipes. Las ideas de Aristóteles estaban muy en boga en la época. En su Política, Aristóteles (1874) distinguía entr140e la realeza ejercida entre los pueblos bárbaros y aquélla que se aplica entre pueblos civilizados. En la primera, el monarca tenía los mismos poderes que la tiranía, que era legítima y hereditaria y su pueblo soportaba el yugo del despotismo "sin dolor ni murmullo". El segundo tipo de realeza era la consentida por los ciudadanos y heredada por la ley. Los fundadores de esta última, eran benefactores del pueblo y habían sido nombrados reyes por gratitud. Aristóteles opinaba que este tipo de realeza era el resultado de la eminente virtud. En definitiva, el objetivo del tirano era su propio interés personal; el del rey la virtud.

La corriente medieval del Espejo de Príncipes definía como principales virtudes de todo gobernante ejercer la justicia y perseguir el bien común.
Estas virtudes hacían que el gobernante fuera obedecido y amado, y lo alejaban de la tiranía. En la Península Ibérica del siglo XVI, estas ideas fueron divulgadas por religiosos como Pedro de Ribadeneyra (1595) y Juan de Mariana (1945). Para estos autores, la tiranía era la última y más execrable forma de gobernar y en ella el soberano-tirano no había sido electo sino que se había apropiado del poder, usurpándolo con violencia y engaño. De Mariana (1945: 81-85) opinaba que el tirano no ejercía mediante procedimientos justos sino que tenía a su pueblo oprimido. No respetaba los tratados y construía y edificaba grandes obras a costa del sudor y lágrimas de sus súbditos. Tampoco defendía las buenas costumbres ni la fe católica. Vemos pues que en el pensamiento de la época el tirano se oponía en todo al señor natural.

Sobre la base de estas ideas, Toledo consideraba que los incas y sus señores étnicos no fueron los legítimos señores antes de la llegada de los españoles. Para legitimar la soberanía de la Corona, Toledo necesitaba forjar un relato de la tiranía de los gobernantes incas y oponerlo a las virtudes de los príncipes cristianos. Los escritos toledanos que manejamos en este estudio consideraron que los señores incas encajaban perfectamente en este modelo de tiranía, y se encargaron de propagar la imagen de que no detentaban el poder legítimamente. Fueron representados como tiranos por la forma en la que habían accedido al poder, puesto que lo habían usurpado, fundado su Estado mediante fraude ya que reivindicaban ser hijos del Sol y habían conquistado el territorio mediante guerras brutales. También fueron tiranos por la forma en la que ejercían su poder 
mediante violencia, esclavizando a su población y disponiendo de ella a su antojo ${ }^{8}$.

Así, tanto el Parecer como la Relación sumaria, señalan como principal responsable de la tiranía inca a Topa Inga Yupanqui y a los señores étnicos. Topa Inga reinó 42 años antes de que llegasen los españoles y parece encajar con la imagen que se había ido forjando del gobernante ilegítimo. Por ejemplo, el Parecer se refiere a él con estas palabras “todo lo ganó y lo conquistó este tirano [...] desde el Cusco ... hasta Quito y Manta por la sierra [...] y por la parte del sur...hasta Chile" (Pérez Fernández, 1995: 139). La intención del Parecer es, como afirma su autor, demostrar que Yupanqui había sido "uno de los mayores tiranos del mundo [...] y que no tenía más dominio en la tierra [...] ni los caciques y curacas eran más señores por haberlos puesto allí un tirano" (Pérez Fernández, 1995: 117). En la Relación sumaria se hace una descripción casi similar de este gobernante. Nos dice en ella Toledo que Topa Inga fue el "primero que conquistó y sujetó tiránicamente a todos los naturales destos reinos, desde esta ciudad de Cuzco hasta las provincias de Chile, y de aquí para abajo hasta la provincia de Quito" (Giménez de la Espada, 1882: 187-188).

Topa Inga Yupanqui es descrito en ambos textos como un cruel sanguinario. En el Parecer va "matando a los que se defendían, hasta no dejar hombre ni niño ni mujer viva [...]. Para asegurar las tierras que ganaba y no se levantase, pasábalos todos a otras partes" (Pérez Fernández, 1995: 140). En la Relación sumaria, Yupanqui aparece descrito de manera casi idéntica como aquél que iba atacando cruelmente a los que no se querían sujetar "matándolos y asolando las tierras [...] y mudando a unos indios de sus tierras a otras para asegurarlos, porque no se tornasen a levantar contra él" (Giménez de la Espada, 1882: 188). Es decir, Topa Inga disponía de su pueblo a su antojo.

Nos parece interesante contraponer la imagen vehiculada de este gobernante en los textos toledanos con la que realizaron cronistas como Pedro Cieza de León y el Inca Garcilaso, que plasmaban una visión radicalmente opuesta, mucho más idílica de él. Cieza de León llegó al Perú en 1548 y conoció de primera mano a la nobleza inca9 ${ }^{9}$. En su crónica, cuando habla de Topa IngaYupanqui, se refiere a él como gobernante respetuoso en sus conquistas y respetado por todos, y no emplea en ningún momento la palabra "tirano". Por ejemplo, dice Cieza que en la conquista de Chucuito:

Mandó proveer de muchos bastimentos y el señor Umalla fue a lo recibir y el Inga le habló bien, así a él como a los demás señores y capitanes [...] Por todas las más partes le llamaban padre y tenía gran cuidado en mandar que ninguno hiciese daño en las tierras por donde pasaba ni fuerzas a ningún hombre ni mujer (2005: 418-421).

El Inca Garcilaso, cronista tardío y gran idealizador de la dinastía Inca, presenta un retrato bastante más embellecido de Topa Inga Yupanqui, presentándolo como un gobernante lleno de virtudes:

Visitó sus reinos por ver por sus ojos las necesidades de los vasallos, para que se remediasen. Las cuales socorría con tanto cuidado que mereció el nombre de pío. En 
estos ejercicios volvió el Príncipe algunos años en suma pazy quietud, servido y amado de los suyos [...] Falleció lleno de hazañas y trofeos, habiendo alargado su imperio más de quinientas leguas a la parte del sur, desde Atacama hasta el río Maulli. Y por la parte del norte más de ciento y cuarenta leguas por la costa, desde Chincha hasta Chimu. Fue llorado con gran sentimiento (Inca Garcilaso, 1985: 140-141).

Volviendo a los escritos que nos ocupan, el afán se pone asimismo en probar que antes de que Topa Inga Yupanqui gobernase no hubo "señor universal ni particular en esta tierra [...] sino todos tiranos y puestos por tiranos" (Pérez Fernández, 1995: 117). Para disipar cualquier duda, el autor del Parecer añade que "ninguna cosa hay en el Perú que mas fatalmente se pruebe, como ahora vuestra excelencia con gran autoridad va haciendo probança" (Pérez Fernández, 1995: 120). Mediante estas aseveraciones se conseguía dar fe de que antes de la llegada de los españoles no había habido señor legítimo ninguno y al haber recibido los monarcas españoles aquellos reinos por atribución papal, eran sus señores universales.

Sin embargo, estos escritos caen permanentemente en un retrato ambivalente de los gobernantes incas. Así, por ejemplo, mientras lo señala como un gran tirano, Toledo presenta a Topa Inga además como "el primero que instituyó la manera de gobierno que agora tienen, proveyendo de curacas, caciques y principales que los mandan y gobiernan" (Giménez de la Espada, 1882: 188). Es decir, Toledo reconoce y elogia el sentido de
Estado de Topa Inga Yupanqui por su capacidad de crear instituciones de gobierno indirecto.

Lo cierto es que al presentar a los incas como señores tiranos, el virrey lo hacía admirando la eficiencia de ciertas estrategias políticas y sociales. Según Mumford (2011: 61) “Toledo demostró cómo las políticas incas encajaban en la definición jurídica de la tiranía; entonces, aparentemente sin notar la ironía, instaba a Felipe II a practicar las mismas políticas". Al igual que Mumford, nosotros creemos que Toledo hizo abstracción de la ironía que suponía encajar ciertas instituciones incas dentro de la organización política del virreinato. Pensamos en consecuencia que el virrey efectuó un giro de estrategia al darse cuenta de que ciertas políticas de los incas, que había tachado de tiránicas bajo el incanato, se ajustaban perfectamente a su proyecto de reforma y a un gobierno legítimo como el de la Corona. Creemos así que para Toledo, tras el traspaso de poder de un jefe tirano a un príncipe virtuoso, se justificaba el mantenimiento de ciertas estructuras de gobierno que habían facilitado la tiranía de los incas. Efectivamente, como afirma Mumford, "no existe ninguna contradicción necesariamente en ensalzar y culpar a la vez prácticas similares en contextos distintos. En la visión española la tiranía y los logros incaicos son difíciles de separar" (2011: 60).

Así, por ejemplo, los mitimaes y la mita, tan denostados por Toledo por representar en tiempos del inca manifestaciones de la tiranía que permitían la ocupación permanente de la mano de obra indígena, fueron requeridos a su vez por él mismo para hacer funcionar el orden colonial. 
Toledo adoptó incluso el método desarrollado por Topa Inga Yupanqui de la visita general del territorio para conocer a fondo a sus gentes. Como los gobernantes incas, Toledo mostró un especial interés por eliminar la ociosidad de los indios teniéndolos ocupados. En una carta a Su Majestad en 1570, manifestaba la necesidad de hacer trabajar a los indios en las minas, vista "la naturaleza de su ocio y el abuso de viçios que tienen” (Levillier, 1921b, III: 348). Y en su Relación sumaria describía cómo algunos testigos admiraban la virtud de los gobernantes incas quienes "conociendo [...] que la inclinación de los indios era estarse holgazanes e ociosos, procuraban con mucho cuidado de hacerlos trabajar, ainsi para que no estuviesen ociosos, porque con esta ociosidad no se alzasen con la tierra" (Giménez de la Espada, 1882: 196). Nos sorprende también que Toledo utilizase la fórmula "con mucho cuidado", con la que creemos que admitía el respeto con que gobernaban los incas, y los reconocía, inconscientemente, como gobernantes virtuosos.

Otro ejemplo de la representación paradójica que los textos toledanos hacían del gobierno eficiente de los incas lo encontramos en el Parecer, donde su autor, al hablar de la tiranía del inca elogia subrepticiamente su sentido civilizador, ya que antes de que éste conquistase todos los señoríos, en su territorio vivían en estado salvaje, no había señor, ni universal ni particular y los indios vivían en behetría "de manera que eran como bestias" (Pérez Fernández, 1995: 142). Como si se tratase del reflejo en un espejo, la Relación sumaria repite casi literalmente la misma idea: hasta Topa Inga Yupanqui, que tuvo y sujetó tiránicamente estos reinos, los dichos naturales no tenían ni tuvieron ningún señor ni cacique que les mandase ni gobernase en tiempo de paz [...] y eran como behetrías, sin que hubiese entre ellos ningún género de gobierno (Giménez de la Espada, 1882: 188).

El autor del Parecer vuelve a caer en la contradicción al admitir de manera manifiesta el sentido de Estado que tuvo Topa Inga al unificar un territorio tan vasto como dispar ya que reconoce que antes de Topa Inga, los naturales estaban divididos y vivían como salvajes "y no tenían fuerça porque no estaban aunados sino con grandes diferencias entre sí mismos" (Pérez Fernández, 1995: 142).

En definitiva, los textos de influencia toledana parecen adoptar por momentos lo que antes habían tachado como inaceptable tiranía, al reconocer que los incas enseñaron a su pueblo a vivir unidos dentro de una organización civilizada y alejada de las behetrías. Se posicionan así casi al mismo nivel que cronistas pro inca de la talla de Garcilaso o Guamán Poma.

\section{Los señores étnicos en los escritos literario-to- ledanos: entre demonización y admiración.}

Los señores étnicos, piedra angular de estos escritos, fueron una de las figuras más desdeñadas y al mismo tiempo idealizadas por el virrey, quien, además de desacreditarlos, supo dotarlos de un papel relevante dentro de sus famosas reducciones, como veremos más adelante. En estos textos abundan las referencias a los caciques y curacas incas, presentándolos como la mayor falsedad del 
dominio de los incas, ya que "son estos caciques tan malos y tan viciosos comúnmente que todo lo llevan tras si [...] y quitalle al rey el poder de hacer elección de los mejores y virtuosos" (Pérez Fernández, 1995: 126). Pensamos que con estas palabras, Toledo manifestaba su voluntad por minar el poder que ciertos caciques habían asumido dentro del orden colonial, como veremos más adelante. El empeño que pone Toledo por desprestigiar a los curacas y principales incas en su literatura roza lo obsesivo y dota a sus escritos, ya sea directamente de su puño y letra o por encargos, de una escritura redundante. En una carta dirigida al Consejo de Indias, Toledo explicaba:

porque [...] de haberse tenido opinión tan confirmada de que el demonio [ ¿dominio?] de losyngas fue de señores ligítimos y naturales y que asimismo los caciques y curacas fueron señores también naturales y que por herencia les venían también los cacicazgos, entiendo que ha sido una de las cosas más perjudiciales [...] del buen gobierno desta tierra (Levillier, 1921b, III: 443).

Según las teorías difundidas por el Parecer, los caciques no habían accedido legítimamente a este título puesto que el tirano que los gobernaba, es decir el Inca, se lo había concedido «a su antojo»:

Topa Inga [...] como tirano dio y repartió a quien quiso, y puso las leyes que se le antojó con su habilidad [...] Daba él y proveía estos estados de caçiques, en muriendo uno, a quien más partes de gobierno tenía [...] y eran tan tiranos como el Inca "porque le ayudaban a sus tiranías" (Pérez Fernández, 1995: 141; 149).

Según la Relación, que reproduce casi las palabras del Parecer, los incas constituyeron su imperio a su antojo, proveyendo "curacas, caciques y principales a que los manden [...]; y que ponía a los dichos cargos a quien quería [...]" (Giménez de la Espada, 1882: 188-189).

Cayendo en la obsesión, en el memorial escrito al finalizar su gobierno, Toledo presentaba a los caciques como a los señores absolutos que supieron tener dominada y sujeta a su población:

Los curacas y caciques principales los tenían tan sujetos que ninguna cosa les mandaban que no la tuviesen por ley; no poseían cosa propia más de lo que los caciques querían [...] y si algún trabajo personal forzoso hacían, era por orden y mandado de los caciques (Beltrán y Rózpide, 1921, I: 87).

Sin embargo, al hablar de la tiranía de los "señores", Toledo y los autores que escribieron bajo su aura vuelven a caer paradójicamente en la emulación, incurriendo en contradicciones. Por ejemplo, subrayan que los cacicazgos no eran hereditarios sino que el Inca ponía y disponía a los caciques que más cualidades reunían para gobernar. Es decir, los señores étnicos gobernaban por méritos y por poseer las cualidades que el Inca estimaba apropiadas para su cargo. Dice el Parecer "Daba él [Inca] y proveía estos estados de caciques, en muriendo uno, a quien más partes tenia para el gobierno [...]. De manera que no tenían esas herencias sino eleçión del Inga teniendo el respeto 
a los hijos y hermanos si hallaba las calidades en ellos para gobernar que eran menester" (Pérez Fernández, 1995: 141). En sus Relaciones, Toledo repetía:

Ansimismo pruébase que quitaba los dichos cargos [caciques] a los que quería y ponía otros en su lugar que le parecía que tenía más habilidad para gobernar; y cuando moría alguno destos curacas [...] cuando no dejaban hijos que tuviesen habilidad para gobernar [...] proveía el dicho Inga a otro indio, cual le parecía de más buen entendimiento [...] sin tener respeto a descendencias ni sucesiones (Giménez de la Espada, 1882: 189).

Los escritos toledanos reconocían, pues, el poder de los señores étnicos durante el periodo inca y lo hicieron extensivo dentro del orden colonial. El autor del Parecer de Yucay, afirmaba así que "puede más un cacique...que çien frailes juntos" (Pérez Fernández, 1995:126). En definitiva, Francisco de Toledo admitió que los caciques conservaban un poder de influencia a nivel político, religioso y moral bajo la dominación española. Así lo manifestaba en un despacho redactado en 1571 que resumimos:

No pueden gobernar estos naturales sin que los caciques sean los instrumentos de la execución, así en lo temporal como en lo espiritual...y puede mas una palabra destos para que dejen sus ídolos y otras maldades, que cien sermones de religiosos [...] si estos caciques son malos llevan tras de sí a toda esta multitud a la imitación de sus vidas [...] Ellos hacen las borracheras y las autorizan
[...] Destos nace el adorar los ídolos [...]; el tener mancebas [...] destos salen los robos y tiranias questos miserables padecen [...] Siempre serán [estos indios] lo que fueren sus caciques y curacas, así en virtudes como en vicios (Lohmann, 1957: 13-14).

Estas ideas aparecen de nuevo plasmadas en el Parecer, cuyo autor no ocultaba su preocupación por la fuerte influencia que ejercían los señores étnicos sobre los indígenas. Se refería a ellos aduciendo que "quien no sabe qué poderosos son estos caciques para hacer buenos y malos a sus indios, [no] entenderá la fuerça de esta raçon" (Pérez Fernández, 1995: 125). Los define como ostentadores de una influencia superlativa, sobre todo en asuntos religiosos, al punto que "si un caçique de éstos, después los indios cristianos, y tenerlos el fraile muy a su mano, les dice: 'mira que es burla todo eso, si no tened las guacas y honradlas', al punto dejarán cuanto el fraile les diese" (Pérez Fernández, 1995: 126-127).

Pero el poder de los caciques podía ser al mismo tiempo un obstáculo para que las autoridades coloniales gobernaran. Efectivamente, el conocimiento que tuvo Toledo del poder e influencia de los señores étnicos lo llevó a sentir la necesidad de establecer leyes y ordenanzas que definiesen y limitasen su autoridad dentro de las reducciones.

\section{Los señores étnicos en el derecho toledano.}

Años antes de la llegada de Toledo al Perú, las autoridades reales y eclesiásticas ya habían manifestado su interés por mantener el estatus de los señores étnicos. Por ejemplo, en las Instrucciones 
dadas al virrey marqués de Cañete, el 10 de marzo de 1555, se explicitaba la voluntad de que "sean restituidos los...caciques en sus indios según antes los tenían [...] porque no es nuestra intención que a los dichos caciques les sea hecho agravio en desmembrarlos sus indios" (Levillier, 1921, II:443). Por su parte, las autoridades eclesiásticas, a través del $2^{\circ}$ Concilio Limense celebrado en 1561 señalaban que "se procuren ganar los curacas, de cuya voluntad y gusto penden los demás sin resistencia ninguna, siendo cosa cierta del todo que la fe y salvación de los indios pende de la voluntad y autoridad de sus caciques" (De Solórzano y Pereyra, 1996: 569). Años más tarde, Lope García de Castro indicaba la necesidad de mantener a los “indios principales"10, para evitar el desasosiego de los indígenas quienes profesaban gran respeto hacia sus caciques (Lohman Villena, 1557: 510).

De aquí podemos inferir que las autoridades coloniales habían tenido tiempo de conocer las funciones atribuidas durante el incanato a los señores étnicos, quienes movilizaban a la población indígena para participar en conquistas, construir infraestructuras, trabajar en las minas y cultivar la tierra en zonas con climas y altitudes diferentes. El virrey Toledo, emulando estas políticas incas, acordó un rol preponderante a los señores étnicos para hacer funcionar las reducciones, recaudar el tributo indígena y movilizar la mano de obra, sobre todo para el trabajo en las minas. También sabía Toledo que sin los señores étnicos de su lado las sublevaciones podrían generalizarse y la evangelización fracasaría. Toledo era, pues, consciente de que la participación de los señores étnicos era indispensable para el futuro del orden colonial, y así lo manifestaba en su carta del 8 de febrero de 1570:

Por muchas cosas es forçoso que los naturales sean gobernados por medio de sus caçiques curacas y principales segun que con ellos los yngas los conservaron en su buen gobierno [...] y que ande ser favoreçidos y amparados en sus cacicazgos y aprovechamientos (Levillier, 1921b, III: 344).

Contrariamente a sus antecesores, Toledo logró materializar su voluntad de acordar un rol pragmático a los caciques a través de sus Ordenanzas, en las que éstos aparecían como elementos bisagra para garantizar las relaciones entre las autoridades españolas y la población indígena. Con este nuevo estatus jurídico que ganaban los señores étnicos, el carácter tiránico que Toledo les había atribuido durante el periodo inca se diluyó al ser éstos reconocidos como verdaderos funcionarios dentro de la legislación colonial y bajo el prestigio de un príncipe cristiano.

Las repetidas referencias a la figura de los caciques en sus Ordenanzas plasmaban la voluntad de definir y conservar su autoridad dentro del marco legal de las reducciones, acordándoles un papel protagónico. En sus Instrucciones para visitadores, el virrey pedía especial cuidado, al formar las reducciones, en que éstas se hicieran "a voluntad y a contento de los caciques" (Lohmann Villena, 1957: 34). En otras disposiciones de sus Ordenanzas, Toledo les otorgaba un rol de "guardianes" de la ley en el seno de las reducciones: 
los dichos indios caciques y principales tengan cuenta, si algunos indios de sus repartimientos se pasasen a otros pueblos, de hacerlos recoger y traer luego a su natural, y por la misma causa no consientan que en sus pueblos estén indios de fuera de ellos, ni los admitan en su servicio (Levillier, 1989: 245).

Al mismo tiempo, estas funciones a menudo iban acompañadas de una serie de prohibiciones y limitaciones con las que manifestaba el virrey su voluntad de que los caciques no abusaran de su poder. Por ejemplo, cuando los caciques se apropiaban de los jornales que debían pagar a los indios, cosa que sucedía frecuentemente. Por eso, el virrey decretó que:

los caciques y principales de los dichos indios no cobre por ellos los dichos jornales [...] ni de otra manera les defrauden de su trabajo, so pena que por la primera vez sean desterrados de las dichas minas y de sus cacicazgos por dos años e por la segunda vez sean privados perpetuamente de sus cacicazgos (Levillier, 1986: 94).

El interés que manifestaba Toledo por garantizar el sosiego de los indios, explica que en 1573, pidiese a los «veedores» (inspectores) de minas que se aseguraran de que esos caciques no robaran los salarios de los indios (Levillier, 1989: 275). No olvidemos que con estas medidas preventivas Toledo buscaba probablemente también evitar que el descontento reinase entre los indios mitayos y que pusiesen en riego el rendimiento económico del virreinato.
Sin dejar de manifestar su voluntad de que los caciques no se enriqueciesen injustamente a costa de los indios, Toledo establecía en sus Ordenanzas de Coca que "ningún cacique, curaca ni principal pueda alquilar indio ni indios de sus pueblos [...] ni el dueño de chácara los pueda concertar ni alquilar con los dichos caciques ni principales aunque digan que lo hacen para pagar su tributo" (Levillier, 1986: 178).

Otra prohibición concernía el porte de armas, estipulado en las Ordenanzas de 1575. En éstas, Toledo mandaba que "ningun cacique, ni principal ni indio particular pueda tener ni tenga armas de españoles [...] y las que tuvieren las manifiesten luego ante el Corregidor para que se vendan" (Levillier, 1989: 256). Pensamos que ésta no era una prohibición anodina, ya que el fin último era probablemente impedir sublevaciones y acentuar la frontera social que separaba los caciques de los funcionarios reales, que sí podían utilizar armas.

Estos ejemplos legislativos, que no son exhaustivos, confieren un marco jurídico a la acción de los caciques, y muestran cuan importantes eran en la sociedad colonial. Además, como representaban la autoridad local, los caciques asumían fácilmente el papel de interlocutores y mediadores entre las autoridades españolas y los indios de sus reducciones. Gracias a la autoridad que les confería su propia comunidad, también coadyuvaron en la evangelización. Como no podía ser de otra manera, Toledo, en su discurso a los caciques de Arequipa, Cuzco y Collao, del 10 de septiembre de 1575, señalaba cuán importante era que los caciques fuesen buenos cristianos para dar "muestra y ejemplo a sus indios" (Levillier, 1986: 
91). Por eso, el virrey hizo todo lo posible para que se instruyera a los hijos de caciques, y puso esta labor en manos de frailes jesuitas principalmente, como había ocurrido en la Península Ibérica con los hijos de las élites moriscas a lo largo del siglo XVI'11. En su memorial dirigido a Felipe II al final de su mandato, Toledo veía en los descendientes de los caciques a futuros agentes para garantizar el orden colonial:

y porque tengo por muy sin duda que los que mas fruto han de tener y pueden hacer en los dichos indios son los caciques y curacas [...] mandé y ordené que fundasen dos colegios, uno en el Cuzco para los indios de la sierra, y otro para los de los llanos en Lima, adonde se criasen y ordenasen los hijos de los caciques (Beltrán y Rózpide, 1921: 75-76).

La utilización de las élites locales en el Perú no era algo nuevo ya que se había gestado mucho tiempo antes en la Península Ibérica, que ya había conocido la experiencia con la minoría musulmana, como acabamos de señalar. Al igual que los caciques andinos, los jefes locales de la comunidad musulmana (cadies, alfaquíes) actuaron como catalizadores para garantizar sus relaciones con las autoridades cristianas en la España de los siglos XIII alXVI. Las élites islámicas representaban el poder local y eran miembros de las familias más poderosas. En el momento de las conversiones, estas élites obtuvieron de las autoridades cristianas funciones institucionales en el seno de sus comunidades. Por ejemplo en el reino de Valencia, las élites locales de la minoría musulmana acostumbraban a negociar ventajas jurídicas para su comunidad con las autoridades cristianas $^{12}$. En la Valencia del siglo XVI todavía era frecuente encontrar señores moriscos (musulmanes convertidos al cristianismo) poderosos, como por ejemplo el jefe de la familia Abdalá Abenamir, juez alcadí de su comunidad, quien mantuvo contactos con destacados miembros de la corte de Carlos V y Felipe II (Benítez SánchezBlanco y Pardo Molero, 2009:180).

A partir de los años 1560, con el "viraje filipino" se produce un cambio de estrategia política hacia las minorías, tanto en la Península Ibérica como en el Nuevo Mundo. Es probable que Toledo se viera a sí mismo como el adalid de la gran reforma colonial. Como lo señala Manfredi Merluzzi (2014: 171), Toledo "tuvo ocasión de legitimar a la Corona, de restablecer nuevas relaciones políticas y estratégicas con la élite indígena local y de perseguir a los disidentes". Así, pensamos que Toledo se erigió como figura central para reafirmar la soberanía de la Corona. Y al reafirmarla, consolidaba al mismo tiempo su autoridad como virrey. Sabido es que el nombramiento de Toledo tuvo mucho que ver con la figura de Juan de Ovando y su proyecto de "entera noticia" (André, 2019). Este proyecto pretendía plasmar una serie de reformas para limitar el poder del Consejo de Indias (Merluzzi, 2014: 74-76) y desarrollar encuestas que permitiesen conocer de primera mano todo lo que acaeciera en las Indias. Toledo debía verse como el mejor candidato a esta tarea.

Por eso, creemos que los escritos toledanos, no sólo sus Ordenanzas, sino también las Relaciones, Informaciones, etc., poseen un alto valor jurídico para legitimar la política toledana frente a sus seguidores pero también frente a voces disidentes, ya 
que a modo de probanzas se enviaban al monarca. Toledo tenía un frente abierto con el Consejo de Indias. El hecho de que hubiese sido designado sin haber pasado por los cauces habituales de consulta al Consejo fue motivo de tensiones con el máximo órgano del gobierno indiano (Sarabia Viejo, 1999: 337). Además, su visita general y su ausencia de Lima durante cinco años le valieron la hostilidad de los Oidores, y numerosas denuncias al Consejo de Indias (Sarabia Viejo, 1999: 117).

Por otra parte, fue también el virrey que más influyó en asuntos eclesiásticos, lo que le valió igualmente la antipatía de muchos de ellos. Toledo promulgó varias cédulas para impedir el regreso a España de muchos clérigos enriquecidos. Esto le valió que muchos de ellos predicaran contra él porque contrariaba sus intereses (Sarabia Viejo, 1999: 123). Y, particularmente, se enfrentaba a las teorías lascasianas defensoras de los indios y muy críticas con las autoridades coloniales, a quienes consideraban usurpadoras del dominio inca.

Por estas razones, pensamos que Toledo tuvo la necesidad de justificar sus acciones, y en este sentido también se explica la prolija actividad legislativa y literaria con la intentaba protegerse. Por otra parte, Toledo sabía que tenía la confianza de las personas más influyentes de la Corona: el Rey, el cardenal Espinosa y Juan de Ovando. Sabía, por lo tanto, que sus escritos gozaban de una alta aceptación, lo que le aportaba mayor legitimidad a sus acciones y desautorizaba a quienes lo cuestionaban. Como señala Roberto Levillier, "sabia Toledo [...] que se trataba de una lucha a muerte con múltiples intereses creados y que le era imprescindible el apoyo leal del soberano, para llevar a buen fin la colosal tarea emprendida" (Levillier, 1935a, I: 129).

\section{Comentarios finales}

A primera vista y a nuestro modo de ver, la trilogía que forman la Relación sumaria, el Parecer $y$ las Ordenanzas de Toledo simbolizan el juicio y sentencia a la tiranía inca, y la implementación del nuevo orden. El Parecer representaría el pensamiento filosófico-jurídico toledano. La Relación sumaria escrita en 1572 y las pruebas testimoniales presentadas en las Informaciones, vendrían a ser la representación del juicio y sentencia dictada a la tiranía inca cuyo veredicto pondría en evidencia la culpabilidad de los incas. Por último, las Ordenanzas instaurarían el nuevo orden definiendo las funciones de los señores étnicos dentro de éste.

Sin embargo, una mirada en profundidad nos permite inferir dos ideas. La primera es que, con estos escritos, Toledo no logra presentar una imagen inequívoca de los señores étnicos y forja dos representaciones contradictorias de ellos. Efectivamente, Toledo construye una imagen denostada de señores étnicos como paladines de la tiranía del sistema político en tiempos del inca, aunque reconociéndoles su capacidad de influir en los indígenas. Sin embargo, una vez convertidos en vasallos de la Corona, Toledo redefine las funciones de los señores étnicos estatuyéndolos como verdaderos agentes coloniales dotados de personalidad jurídica, y reconociéndolos como elementos indispensables para el control y movilización de la masa indígena. Este reconocimiento, sin embargo, no estuvo exento de limitaciones de 
sus derechos y obligaciones dentro de un marco legal muy preciso. Haciendo alarde de sus capacidades estratégicas y jurídicas, Toledo confirió a los señores étnicos un estatus protagónico y les reconoció la legitimidad de la que carecían, según él, durante el incanato.

La segunda idea que concluimos nos lleva a afirmar que la producción literario-jurídica toledana contenía un fuerte simbolismo legitimista para su acción reformadora. Tanto sus propias obras (su visita general, las Informaciones, sus Instrucciones para visitadores, sus Ordenanzas), como sus encargos (El parecer Anónimo, la Historia Indica, y Los Paños incas, confiados a varios pintores indígenas) formaron parte de una estrategia personal que reforzaba su actividad como virrey. Con sus escritos Toledo construye una nueva escritura puesta al servicio de los intereses de la Corona y de sus propios intereses.

\section{Referencias citadas}

André, S. (2019): “El momento ovandino. De la empresa de saber a la fábrica de la acción”, e-Spania [En línea], 33. Disponible en web: https://journals.openedition. org/e-spania/30715 [ Consulta: 30 septiembre 2020].

Aristóteles (1874): Politique Traduite en Français par Barthélemy Saint Hilaire, Paris, Librairie Philosophique de Ladrange, 3a edición. Disponible en web: http://remacle.org/bloodwolf/philosophes/Aristote/ tablepolitique.htm [Consulta: 2 octubre 2020].

Beltrán y Rózpide, R. (1921): Colección de las memorias y relaciones que escribieron los virreyes del Perú acerca del estado en que dejaban las cosas generales del reino,
Madrid, Biblioteca de Historia Hispanoamericana, vol. I, Imprenta del asilo de Huérfanos del S.C de Jesús.

Benítez Sánchez-Blanco, R.y J.F Pardo Molero (2009): "Obstacles à l'intégration des morisques du royaume de Valence. Discrimination légale et résistance morisque", Cahiers de la Méditerranée, 79, pp. 171-194.

Cieza de León, P. (2005[1880]): El señorío de los Incas, Caracas, Biblioteca de Ayacucho.

De Mariana, J. (1945[1599]): Del rey y de la institución de la dignidad real, Benos Aires, Editorial Partenón.

De las Casas, B. (1958 [1565]): "Memorial al Consejo de Indias en Juan Pérez de Tudela, Obras escogidas de Fray Bartolomé de las Casas. Opúsculos, cartas y memoriales", Madrid, Biblioteca de autores españoles, t. CX.

De Ribadeneyra, P. (1595): Tratado de la religion y virtudes que deue tener el principe christiano, para gouernar y conseruar sus estados: contra lo que Nicolas Machiaueloy los politicos deste tiempo enseñan, Madrid, Imprenta de P. Madrigal.

De Solórzano y Pereyra, J. (1996 [1647]): Política Indiana, Madrid, Biblioteca Castro.

El Alaoui, Y. (2006): Jésuites, Morisques et Indiens. Etude comparative des méthodes d'évangélisation de la Compagnie de Jésus d'après les traités de José de Acosta (1588) et d'Ignacio de las Casas (1605-1607), Paris, Honoré Champion éditeur.

Espinosa Soriano, W. (1984): La destrucción del imperio de los incas, Breña, Amaru editores SA. 
Giménez de la Espada, M. (1882): "Relación sumaria de lo que se contiene la Información de la tiranía de los Ingas" [Hecha por Francisco de Toledo], en Fernando Montesinos ed., Colección de libros españoles raros o curiosos, tomo XVI, Madrid, Imprenta de Miguel Ginesta.

González, S. y J. Zuleta (2019): “Narración y argumentación en la Historia índica (1572) de Pedro Sarmiento de Gamboa", Revista Estudios Atacameños, 61, pp. 27-47.

Inca Garcilaso, (1985 [1609]): Primera parte de los Comentarios Reales, Caracas, vol. I, Biblioteca de Ayacucho.

Levillier, R. (1921a): Gobernantes del Perú. Cartas y papeles del siglo XVI, vol. II, Madrid, Sucesores de Ribadeneyra.

Levillier, R. (1921b): Gobernantes del Perú. Cartas y papeles del siglo XVI, vol. III, Madrid, Sucesores de Ribadeneyra.

Levillier, R. (1935a): Don Francisco de Toledo, Supremo organizador del Perú, vol. I, Madrid, Espasa Calpe.

Levillier, R. (1935b): Don Francisco de Toledo, Supremo organizador del Perú, vol.III, Madrid, Imprenta de Juan Pueyo Luna.

Levillier,R. (1986): Disposiciones Gubernativas parael virreinato del Perú, 1569-1574, vol. I, Sevilla, CESIC.

Levillier,R. ( 1989): Disposiciones gubernativas para el virreinato del Perú. 1575-1580, vol. II, Sevilla, CSIC.

Lohmann Villena, G. (1957): El corregidor de indios en el Perú, Madrid, Ediciones cultura hispánica.
Merluzzi, M. (2008a): “Memoria histórica y gobierno imperial. La revisión historiográfica toledana y la "reconquista" del Perú" en Memoria histórica y gobierno imperial. Las Informaciones sobre el origen y descendecia del gobierno de los Incas, Rosario, Prohistoria, pp.7-54.

Merluzzi, M. (2008b): La pacificazione del regno. Negoziazione e creazione del consenso in Peru (15331581), Roma, Viella

Merluzzi, M. (2014): Gobernando los Andes. Francisco de Toledo virrey del Perú (1569-1581), Lima, Fondo editorial Universidad Católica del Perú.

Millones-Figueroa, L. (1998): “De Señores Naturales a Tiranos: El Concepto Político De Los Incas y Sus Cronistas En El Siglo XVI", Latin American Literary Review, 26 (52), pp.72-99. Disponible en web: https:// www.jstor.org/stable/20119785?seq=1 [Consulta: 20 octubre 2020].

Morong, G. (2001). "Textualidad hispana y dominación colonial; la construcción de la legitimidad hispana por el dominio del Tawantinsuyu, durante la administración toledana 1567-1572”, Anuario de Post-Grado, 4, pp. 267-300.

Morong, G. (2013): "De la natural condición e inclinación de los indios; el oidor Matienzo y su proyecto de gobernabilidad para el Perú virreinal, 1567”, Diálogo Andino, $\mathrm{N}^{\circ} 42$, pp.17-30.

Morong, G. y V. Brangier. (2019): “Los Incas como ejemplo de sujeción. El gobierno del Perú y la escritura etnográfica del oidor de Charcas, Juan de Matienzo (1567)", Estudios atacameños, 61, pp. 5-26. 
Mumford, J. (2011): “Francisco de Toledo, admirador y émulo de la «tiranía» inca”, Histórica, XXXV (2), pp. 45-67. Disponible en web: http://revistas.pucp.edu.pe/ index.php/historica/article/view/3794 [Consulta:22 octubre2020].

Mustapha, M. (1977): “Encore le 'Parecer de Yucay': essai d'attribution", Ibero-amerikanisches Archiv, 3 (2), pp. 223-229. Disponible en web: https://www.jstor.org/ stable/43751497? seq=1 [Consulta: 2 noviembre 2020].

Pérez Fernández, I. (1995): El anónimo de Yucay frente a Bartolomé de las Casas. Estudio y edición crítica del Parecer de Yucay, anónimo (Valle de Yucay, 16 de marzo de 1571), Cusco, Centro de Estudios Regionales Andinos "Bartolomé de las Casas".

Platt, T. (1982): Estado boliviano y ayllu andino. Tierra y tributo en el norte de Potosí, Lima, Instituto de Estudios Peruanos.

Ramos, D. (1986): “La crisis indiana y la Junta Magna de 1568", Jahrbuch für Geschichte Lateinamerikas [Anuario de Historia de América Latina], 23, 1986, pp. 1-61.

Sarabia Viejo, M. J. (1999): “Luis de Velasco el viejo y Francisco de Toledo: dos tipologías virreinales de la América de Felipe II", Chronica Nova, 26, pp.333-345.

Tandeter, E. (1992): Coacción y mercado. La minería de la plata en el Potosí colonial, 1692-1826, Cuzco, Centro de Estudios regionales Andinos.

Wachtel, N. (1971): La vision des vaincus, Paris, Gallimard.
Zuloaga Rada, M. (2012): La conquista negociada: guarangas, autoridades locales e imperio en Huaylas, Perú (1532-1610), Lima, Instituto de Estudios Peruanos.

\section{Notas}

${ }^{1}$ Hacia 1536, Manco Inca había protagonizado en el Cuzco el primer levantamiento organizado contra la dominación española, el cual había desembocado en la huida del Inca a la región de Vilcabamba. Allí instauró el estado neo-inca, bastión de resistencia indígena que perduró hasta 1572. Ya en los años 1560 circulaban numerosos rumores que situaban a Vilcabamba como el centro de operaciones de un complot general contra los españoles. Felipe de Segovia Briceño, propietario del obraje La Mejorada en la región de Jauja escribía en una carta dirigida al gobernador García de Castro: "Los caciques y principales con los indios de este reino desde Chile hasta Quito, están alzados contra Dios y contra tu rey, y tienen tratado, y concertado de alzarse con el reino [en 1565], y matar a cuantos españoles hay en él”, en Vargas Ugarte (1966: 304-305).

${ }^{2}$ Para todo lo referente a la celebración de la Junta Magna, consultar los trabajos de: Merluzzi (2010, 2014); Ramos (1986).

${ }^{3}$ En adelante nos referiremos a él como el Parecer.

${ }^{4}$ En adelante, Relación sumaria.

${ }^{5}$ Referente a Historia Indica sugerimos la lectura de González y Zuleta (2019).

${ }^{6}$ Giménez de la Espada publicó en Memorias antiguas historiales y políticas del Perú (1882), la Relación sumaria de lo que se contiene la Información de la 
tiranía de los Ingas y 6 de las 11 Informaciones que realizó Francisco de Toledo: Información hecha en Jauja a 20 de noviembre de 1570; Información hecha en Huamanga a 14 de diciembre de 1570; Información hecha en el Cuzco a 13 de marzo de 1571; Información hecha en el valle de Yucay a 19 de marzo de 1571; Información hecha en el Cuzco a 22 de febrero de 1572; Información hecha en Cuzco a 2 de enero de 1572. Además de la Relación Sumaria y las Informaciones, la publicación contiene una carta de Toledo escrita en el Cuzco, dirigida al Consejo de Indias y fechada en 1 de marzo de 1572.

${ }^{7}$ El texto original de El Parecer Anónimo de Yucay se perdió y las copias no fueron firmadas, por lo que ha sido atribuido durante años a diferentes personalidades cercanas al virrey como Pedro Sarmiento de Gamboa, Juan Polo de Ondegardo, incluso Pedro Cieza de León.

${ }^{8}$ Sobre la tiranía de los incas, véanse también los trabajos de Morong (2001, 2013); Morong y Brangier (2019); Mumford (2011).

${ }^{9}$ Luis Millones ha realizado un estudio sobre esta idea comparando la intertextualidad entre el Señorío de los Incas de Pedro Cieza de León y la Historia Índica de Pedro Sarmiento de Gamboa. Millones-Figueroa (1998).

${ }^{10} \mathrm{La}$ intención de Lope García de Castro era que los Corregidores de indios fueran ganando autoridad sobre los caciques y los encomenderos.

${ }^{11} \mathrm{~A}$ este respecto, consultar el trabajo de El Alaoui (2006).

${ }^{12}$ Un estudio comparado de las élites indígenas y musulmanas ha sido realizado por Natividad Ferri Carreres su tesis doctoral, Les minorités, l'espace et le droit: Indiens et Morisques dans la configuration territoriale de l'Empire Ibérique, Université de Caen-Normandie (Francia), 2017. 